\title{
Doctors endorse development of patient charter
}

Published at www.cmaj.ca on Aug. 25

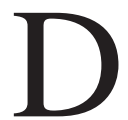

octors gave overwhelming support to the development of a national patient charter and other patient-friendly initiatives at the Canadian Medical Association's 143rd annual general meeting in Niagara Falls, Ontario.

They also urged Canadian educators to revise medical school curricula to better prepare future doctors to provide patient-centred care but sought to curb the parameters of a motion calling on CMA to study how end-of-life and palliative care fits into the picture for fear it might raise the contentious issues of euthanasia and doctor-assisted suicide.

They were eager, though, to encourage more work on the development of a charter of patient rights in partnership with provincial medical associations, patient advocacy groups and other medical and health organizations. The delegates voted $97 \%$ in favour of that effort during a strategic session on patient-centred care on Monday.

The move drew the praise of a leading patient advocate, who called the charter a "covenant" between doctors and the Canadian public.

"If we are all driven by the gold standard in terms of that transformation, I think we will end up with a system that does put patients at the very centre," said Durhane Wong-Reiger, president and CEO of the Institute for Optimizing Health Outcomes.

But she warned that a patient charter will be "meaningless" if not backed by legislation.

Some 250 delegates representing 73000 CMA members from across Canada directed the association to conduct a review of "the international experience with the implementation of patient charters and related instruments" in order to "develop options for accountability."

International experience with patient charters indicates that nonbinding rights have limited utility, while

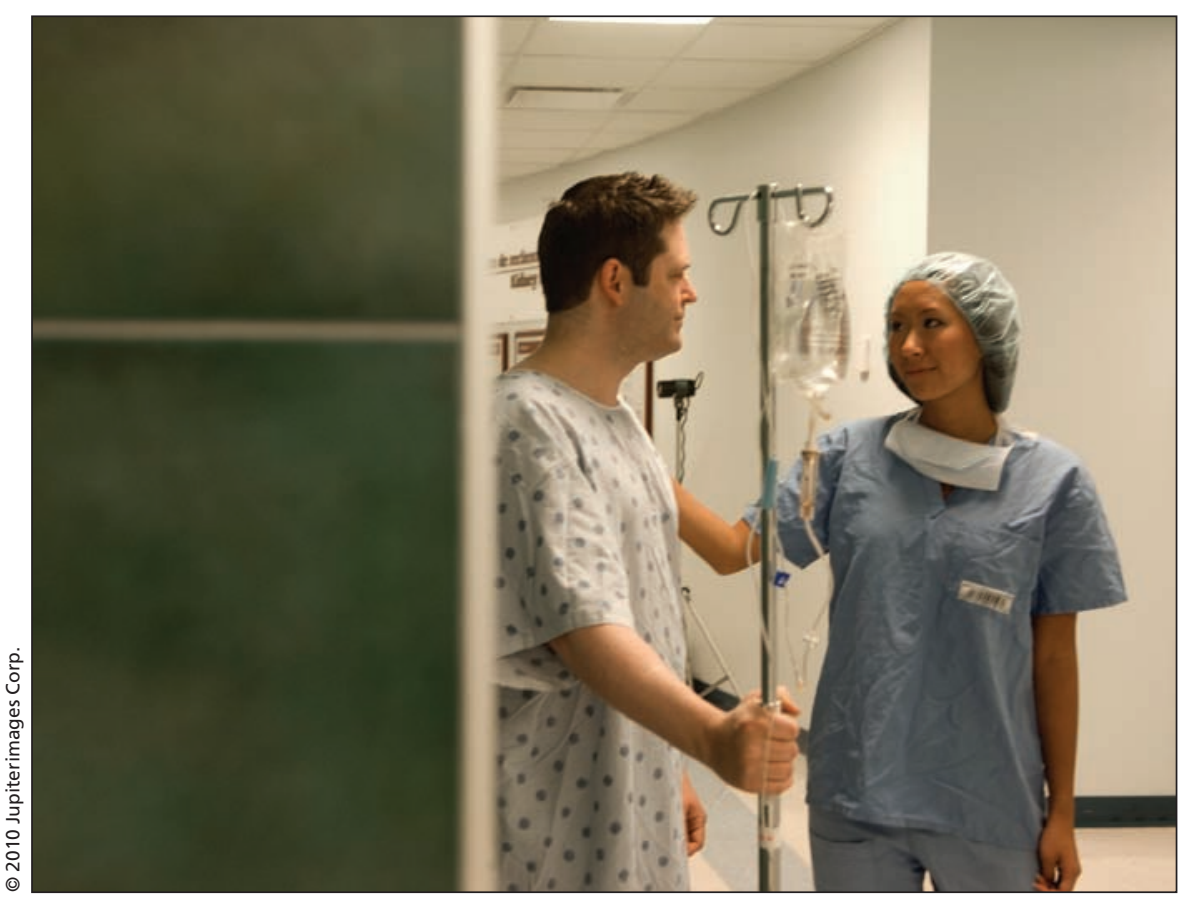

Canadian doctors agree: the focus in health care should be on the patient. At the Canadian Medical Association's 143rd annual general meeting, delegates voted $97 \%$ in favour of the development of a charter of patient rights in partnership with provincial medical associations, patient advocacy groups and other medical and health organizations.

efforts to quantify the efficacy of such charters have often been hampered by the fact that accountability metrics are often embryonic, if not nonexistent (www.cmaj.ca/cgi/doi/10.1503/cmaj .109-3342).

It's hoped that the federal and provincial governments will eventually clamber aboard the charter train.

Delegates also called upon the Association of Faculties of Medicine of Canada, College of Family Physicians of Canada, Royal College of Physicians and Surgeons of Canada, and the nation's 17 medical faculties to refine and utilize the concepts of patient-centred care "in the teaching and training of medical students and residents."

They also directed CMA to conduct an "intensive" health literacy campaign among physicians and to work with governments and other medical associations to ensure that patient-focused funding initiatives are evidence-based and "support the timeliness, safety and quality of patient care."

However, discussion bogged down around proposals relating to end-of-life care.

Delegates somewhat reluctantly voted (65 in favour, 25 opposed, and 8 abstentions) to endorse the inclusion of "appropriate end-of-life and palliative care" among patient rights sketched in CMA's blueprint for health care transformation.

More contentious was a motion compelling CMA to "undertake a comprehensive study to identify and document end-of-life practices in Canada to shed light on the debate surrounding the issue."

Several delegates feared the emphasis on "debate" would create the perception that the association was investing in research on euthanasia and doctor-assisted suicide.

"Nobody really knew what the 
debate was and what dark holes the light had to go into. I wasn't in a position or informed to discuss any of the issues around physician-assisted suicide or euthanasia, which are very sensitive issues," says CMA PresidentElect Dr. John Haggie, a delegate from Newfoundland and Labrador.

The delegates quickly scotched all reference to "debate," giving CMA the green light to conduct only "a study to identify and document end-of-life practices."

"It was a matter of less is more," says Haggie. "There are huge gaps in care based on where you live, and demographic changes have added an extra urgency to that."

Delegates were also apprised of a CMA-commissioned poll that found that four in every five Canadians believe the demands placed on the health care system by aging baby boomers will result in reduced access and lower quality care (www.cma.ca /advocacy/silver-tsunami).

Close to $75 \%$ of respondents also feared growing health costs will result in significant tax hikes and an inability of senior citizens to afford health care. — Lauren Vogel, CMAJ

DOI:10.1503/cmaj.109-3354 